\title{
eJRIEPS
}

Ejournal de la recherche sur l'intervention en éducation physique et sport

$18 \mid 2009$

Varia

\section{The Idea of the Idea of Physical Education: Between essentialism and relativism in studying the social construction of physical education}

\section{David Kirk}

\section{OpenEdition}

1 Journals

\section{Electronic version}

URL: http://journals.openedition.org/ejrieps/5482

DOI: 10.4000/ejrieps.5482

ISSN: 2105-0821

\section{Publisher}

ELLIADD

Electronic reference

David Kirk, "The Idea of the Idea of Physical Education: Between essentialism and relativism in studying the social construction of physical education", eJRIEPS [Online], 18 | 2009, Online since 01 July 2009, connection on 18 March 2021. URL: http://journals.openedition.org/ejrieps/5482 ; DOI: https://doi.org/10.4000/ejrieps.5482

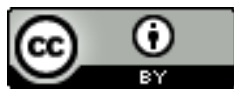

La revue eJRIEPS est mise à disposition selon les termes de la Creative Commons Attribution 4.0 International License. 
The Idea of the Idea of Physical Education: Between essentialism and relativism in studying the social construction of physical education

David Kirk

Faculty of Education \& Sport, University of Bedfordshire.

Bedford MK41 9EA. United Kingdom

Ce texte est la conférence prononcée par David Kirk au Séminaire International de l'AIESEP à Besançon le 27 mai 2009.

Cultural and historical judgement cannot be left to 'the past' alone, since the particular picture of the past which is invoked is the one selected by these very judgements.

Chanan and Gilchrist, 1974, p. 62

In a book which will be published by Routledge in July, I make extensive use of the notion of 'the idea of the idea' of physical education to consider the significance of the past and the present for physical education futures (Kirk, 2009). For the sake of brevity, I shortened this concept to the $\mathrm{id}^{2}$ of physical education. The $\mathrm{id}^{2}$ builds on earlier historical work published in Defining Physical Education (Kirk, 1992a) and Schooling Bodies (Kirk, 1998). In these studies I argued that physical education is socially constructed in the sense that it is a human invention rather than an occurrence in nature. More than this, and following Goodson's (1997) lead, I proposed that this process of social construction involves struggles over resources between vying groups. Building on insights from 'new directions' sociology of education (Young, 1971; Evans, 1986), which was itself a reaction to a particular approach to the philosophy of education fashionable in the 1960s and 1970s, this work sought to show the importance of human action within particular local and, increasingly, global contexts in determining the form and content of physical education.

Demonstrating that physical education was socially constructed, however, admitted the possibility of relativism. In contrast to one version of analytical philosophy of education in which key concepts were considered to possess essential, transcendental characteristics, or to be constituent of 'the rational mind', relativism suggests instead that concepts have multiple meanings that are context-bound. As Chanan and Gilchrist (1974) note, construction of 'a past' is a selection from possible other 'pasts' and is thus value-laden. In an extreme form of relativism, there is no basis on which to differentiate among this 
multiplicity of meaning. If knowledge is socially constructed, physical education can be whatever I decide. No-one's definition is better than anyone else's; in other words, anything goes (Whitty, 1985).

While a social constructionist perspective on physical education may admit to the possibility of relativism, it does not endorse this extreme perspective as inevitable or desirable. It does create a challenge for social epistemology, though, a challenge that needs to be acknowledged and wrestled with, if not completely resolved. If, as I will argue here, physical education has no essential, transcendental characteristics since the historical record shows it has changed over time, how then are we to avoid the position at the other extreme, that it has no meaning at all or, at least, only the meaning we arbitrarily select and choose to give it? From a social epistemological perspective, we might point out that something called 'physical education' is practiced in particular locales at specific times. What physical education 'means' is embedded in and expressed through the interactions of the participants; the teachers and students, the designers of lessons and programmes, the builders of facilities and the creators and suppliers of equipment, just to name a few. If physical education has no essence, no features which transcend time and space, how can we recognize its occurrence in these context-bound instantiations of interactions of teachers and students around subject matter, using equipment in spaces such as gyms and playing fields?

This is the question this paper seeks to address, at least to a level that can satisfactorily permit a study of the social construction of physical education to be undertaken. In this paper, I want to outline how the $\mathrm{id}^{2}$ might be deployed in this programme of study, how it is intended to be understood, as a means of dealing with the tension between essentialist and relativist perspectives. An obvious issue that needs to be examined first of all is why the statement of a definition of physical education does not seem to resolve the matter of what physical education means, particularly when according to Laker (2003), Penney and Chandler (2000), Locke (1992), among many others, definitions abound. I then go on to provide a context within social epistemology and curriculum history to develop the id ${ }^{2}$ from the work of Rothblatt (1997), with support from Bernstein's (2000) theory of the social construction of pedagogic discourse. The paper concludes with a short discussion of four relational issues which form the key dimensions of the $i d^{2}$ of physical education.

\section{Definitions of physical education}

The most common and straightforward approach to defining physical education is, simply, to state a definition of physical education. Defining physical education has been something 
of a pre-occupation of physical educators, pre-dating the emergence of the term itself in modern usage, with A.D. Munrow (1963) devoting a whole chapter of his book Pure and Applied Gymnastics, first published in 1955, to the question 'What is Gymnastics?'. There are many definitions of physical education in existence today which vary in specificity, explicitness and scope. Some make links between learning in the physical domain and a range of related outcomes concerned with physical and social skills, moral values, health, spirituality and intellectual ability. Penney and Chandler (2000) express concern that, while physical educators seem to be agreed on what physical education is not,

The matter of what the core aims of the subject are remains far less clear and a source of apparent tension. Claims about the contribution of the subject to children's development, later lives and to society are multiple and diverse ...(we)... question the degree to which physical education can legitimately continue to make varied claims and pursue multiple agendas.

(Penney and Chandler, 2000, pp.74-5)

In Physical Education Futures I noted that these claims for physical education and the definitions they either explicitly or implicitly announce provide an impression that the field is conflict-ridden, that it is indeed a good example of extreme relativism with its 'varied and multiple agendas'. While it may be accurate to say this in a very specific sense, my comment in the book was that much (though not all) of this apparent dissent misses the point, since it has done little to seriously challenge the currently dominant $\mathrm{id}^{2}$ of physical education-as-sport-techniques. I argued, moreover, the differences in the practice of physical education in economically advanced countries and regions are for the most part less significant than the similarities.

For these reasons, an exhaustive examination of the many definitions that abound is unnecessary because they give a misleading impression that there is more diversity of practice than in fact exists. It may be helpful, nonetheless, to gain some sense of the kinds of definitions that have been offered for physical education if only to appreciate why this is the least satisfactory means of defining physical education.

Writing in 1951 in the USA, Brownell and Hagman helpfully offered a definition of a definition by reasoning that "a definition should explain the meaning or properties of a word or phrase that show its distinguishing features and point out its relationships to other things of an associated nature." (Brownell and Hagman, 1951, p.17) They acknowledge that definitions should reflect the purposes of the writer, and since writers may vary in their 
purposes for physical education, for example one emphasising physical fitness with another stressing recreational outcomes, their definitions may also vary. Brownell and Hagman's own definition of physical education was intended to contribute to the goals of education more generally while identifying physical education's unique contribution; thus, "physical education is the accumulation of whole-some experiences through participation in large-muscle activities that promote optimum growth and development" (Brownell and Hagman, 1951, p.17).

This is a relatively broad definition that identifies some properties of physical education such as 'whole-some experiences' and 'large-muscle activities', while leaving much scope for what learning experiences and subject matter in particular might be selected to construct a programme. We can compare it to a definition provided by English physical educator Martin Randall, also writing originally in the early 1950s but still current in a third edition of his book in the late 1960s. Randall argued that the ultimate aim of physical education was to contribute to the overall education of young people. In this context, "physical education ... covers the whole field of physical activity, all sports and pastimes, in and out of doors, of a competitive or recreational character involving either team cooperation or individual effort. Its variety is infinite" (Randall, 1967, p.32). Randall is rather more substantive and content-specific than Brownell and Hagman, making explicit reference to sport, recreation and other pastimes indoors and out, though no mention is made of outcomes such as health or fitness implied in the Americans' 'optimum growth and development', while the inclusion of only 'whole-some' activities is no doubt assumed. A somewhat more sophisticated definition is offered by Morgan (1973) in a sustained argument in his book Concerns and Values in Physical Education. After careful consideration of a number of possibilities, Morgan (1973, p.9) chooses as his preferred definition that physical education is "education through athletic forms of activity". The characterization of forms of activity as 'athletic' was intended by Morgan to provide a means of linking the riskily disparate categories of physical activities such as sport, gymnastics and dance. Like Randall, Morgan expressed the view that physical education must contribute to the broader aims of education. In order to do so, he suggested that the concerns and values that identified physical education's contribution to education were enjoyment and satisfaction, skill, beauty, fitness and health, and mind and character.

More recently, the definition of physical education that will guide physical educators in schools in England and Wales from 2008 can be found in The National Curriculum for England: Physical Education. 
PE develops pupils' competence and confidence to take part in a range of physical activities that become a central part of their lives, both in and out of school ... A highquality PE curriculum enables all pupils to enjoy and succeed in many kinds of physical activity. They develop a wide range of skills and the ability to use tactics, strategies and compositional ideas to perform successfully.

When they are performing, they think about what they are doing, analyse the situation and make decisions. They also reflect on their own and others' performances and find ways to improve them. As a result, they develop the confidence to take part in different physical activities and learn about the value of healthy, active lifestyles. Discovering what they like to do, what their aptitudes are at school, and how and where to get involved in physical activity helps them make informed choices about lifelong physical activity.

PE helps pupils develop personally and socially. They work as individuals, in groups and in teams, developing concepts of fairness and of personal and social responsibility. They take on different roles and responsibilities, including leadership, coaching and officiating. Through the range of experiences that PE offers, they learn how to be effective in competitive, creative and challenging situations.

(Qualifications and Curriculum Authority, 2007, www.nc.uk.net)

We can see some commonality between these definitions, but only at a relatively abstract level. All mention 'physical', 'athletic' or 'large-muscle' activities. Three mention or imply health as an outcome. Two others refer to competition. The QCA's and Morgan's definitions include cognitive processes such as confidence, attitudes and learning to think, though only Morgan's and Randall's mention sport explicitly. Insofar as they together map out the field or define the subject, these links may be judged to be somewhat tenuous at a written level. Far more problematic is the large variability in the kinds of programmes that might result from these definitions in practice. This variability should at least challenge our thinking about what practices might count as 'physical education', the issue that is the central concern of this paper.

As definitions go, the QCA version is very carefully worded. It provides enough information about the content of the subject to differentiate it from other subjects, but at the same time allows us to imagine how links to other subjects might be made. It also contains information on outcomes, in terms of what pupils should be able to do, and so is in this sense aspirational. In technical terms, as a piece of curriculum writing, it could be viewed as a 'good' definition. But why should we accept this definition over the many other just as 
well written definitions that are available, particularly since it rather bizarrely and for most people (I imagine) unexpectedly, fails to mention sport explicitly? In this sense, far from stating what physical education is definitively, it could be argued that the act of stating definitions such as this in fact contributes to relativism instead, to the idea that there can be a proliferation of definitions. To be sure, as Brownell and Hagman note, definitions will reflect individual purposes. But, as Penney and Chandler protest, how many purposes can physical educators be permitted to pursue while describing what they do as physical education? This proliferation of definitions in turn creates a problem of credibility. For example, how can an organization such as the QCA offer a definition that omits to mention sport while, as I show in Physical Education Futures, the teaching of sport-techniques has been the substance of the subject since at least the 1950s? What kind of subject is it that cannot agree on its 'essential' character?

The mere statement of a definition, no matter how well crafted, is of limited assistance in defining physical education. The proliferation of definitions may in any case be counterproductive to gaining a better understanding of physical education past, present and future. Rather than capture the 'essence' of physical education, the sheer quantity and dissimilarity of definitions may encourage an extreme relativist attitude instead, where one definition is as good as any other and, thus, anything goes.

\section{Analytical philosophy of education, social epistemology and curriculum history}

Epistemology is the study of the nature of knowledge. For scholars of education, it is a field of study of central importance. Since the beginning of formally organised school education funded by governments, limited resources have forced educational policymakers to confront epistemological questions such as which knowledge is of most worth, and related questions such as which knowledge should children be required to study or, in other words, what should be its 'core', what should be optional, and how should the school curriculum be organised? In the late 1950s through to the 1970s, English-language analytical philosophers of education grappled with these epistemological questions, developing an approach that involved the analysis of concepts such as education.

The work of British philosopher Richard Peters was particularly influential. Peters (1966) argued that education involved initiation into worthwhile activities. An educationally worthwhile activity, according to Peters, is of value for its own sake. We can recognize such activities, claimed Peters, since they will be 'serious' in the sense that they will inform other areas of life, they will offer a cognitive perspective on the world with wide-ranging cognitive content, they have the capacity to enrich and change a person's view of the 
world, and they will illuminate the truth. Furthermore, worthwhile activities are transcendental in the sense that they are forever and always worthwhile, regardless of time and place.

Peters and others (White, 1973; Hirst, 1974) were taken seriously by educational policymakers and their advisors (eg., Lawton, 1993; Skilbeck, 1984). While they did not necessarily agree with all of the detail, the curriculum-makers accepted the main implications, such as the possibility of distinguishing between what knowledge should be in the school curriculum and what should not. This philosophising may have seemed some distance removed from the 'real world' of schools but it had very serious potential consequences for the perceived educational status of activities such as physical education, which predictably failed to make the philosophers' list of essential subjects. Interestingly, wherever the core curriculum idea was applied, for example in mid-1970s Scotland (SED/CCC, 1977) and in Australia in the 1990s (NPDPHPE Project, 1997), physical education managed to retain the status of a required subject in secondary schools, though typically with less time than most other core subjects, but nevertheless suggesting that this approach to epistemology had limited impact in the longer term. This analytical approach is at the same time important to our task here, as we will see momentarily.

As the popularity and influence of analytical philosophy of education reached its height around the early 1970s, a challenge presented itself in the form 'new directions' sociology of education. Research in the sociology of school knowledge, particularly as it began to take shape in the work of writers such as M.F.D. Young, Basil Bernstein, Pierre Bourdieu and Geoff Esland (see Young, 1971), put forward the radical proposition that the school curriculum is an example of the social organization of knowledge. This proposition suggested that rather than school knowledge possessing an intrinsic worth that transcends societies and historical epochs, as the analytical philosophers had it, the knowledge that constructs and constitutes the school curriculum is the product of a range of social forces, involving the exercise of power and embodying particular values and beliefs.

The full significance of this insight was brought out in the work of school curriculum historians such as Kliebard (1986) and Goodson (1985), and university curriculum researchers such as Rothblatt (1997) and Becher and Trowler (2001). Goodson proposed that school subjects and university disciplines follow trajectories of popularity and perceived importance over time through struggles between vying groups and individuals who actively contest each others' values and seek to establish their own preferences for particular versions of school knowledge. The message of this social epistemological 
approach was that, if we wish to define a field or subject such as physical education (or geography or mathematics), we must, as Becher and Trowler (2001) suggested, study what people do in the name of that subject.

Curriculum history research seemed to support an anti-essentialist position by demonstrating empirically that not only did the fortunes of subjects wax and wane, but that their form and substance also changed over time. A social epistemological approach to the curriculum is left with a problem to deal with nevertheless. While this approach suggests there is no enduring 'essence' of physical education, there must still remain some means of recognising when a practice is physical education and when it is something else, say, active leisure or sports coaching. So while there can be no unchanging, immutable, transcendental, essential physical education, a practice needs to have some distinguishing physical education-ness in order to be recognized as physical education. Sheldon Rothblatt's attempt to confront this difficulty in his historical research on the university provides us with a possible means of grappling with this challenge.

\section{The idea of the idea of the university}

The id ${ }^{2}$ of physical education owes a debt to Rothblatt (1997) and his book The Modern University and Its Discontents. Rothblatt (1997, p.36) noted that for centuries universities have been in the habit of re-inventing themselves in order to remain current and to garner prestige. In these circumstances of regular re-invention, what is it, he asks, that allows us to recognize an educational institution as a 'university'? In order to answer this question, Rothblatt turns to the famous definition of the university provided by John Henry (later Cardinal) Newman in his book The Idea of a University, written in the 1850s. The university, stated Newman, is a place for teaching universal knowledge. "Such is a University in its essence." Rothblatt shows that Newman's definition had strong resonance with the Oxford of Newman's undergraduate days some thirty years earlier and as such the teaching was focused on the cultivation of character rather than the mere acquisition of expertise. But by the time of writing The Idea, this notion, that the university was primarily concerned with teaching, was already under threat at Oxford as research grew in importance. Moreover, by the 1850s, there were other, rival notions of the university emanating from Germany, the United States, Ireland and from neighbouring Scotland.

Newman's legacy was not then his actual definition of the university, since there existed in the 1850s and exist now many examples that do not match this precise definition. According to Rothblatt, the importance of Newman's contribution to the history of the university is the idea of the idea of the university. While there is in fact no essence that 
distinguishes universities from other kinds of educational institutions and educational institutions from factories, since universities and other educational institutions and factories are regularly changing, the idea of the idea presents the possibility that there could be an essence. In other words, the idea of the idea is a kind of as if proposition, that imagines the possibility of some essential characteristics that make universities recognisable as universities without locking them forever into a definition that states unequivocally 'the university is a place for teaching universal knowledge'.

Rothblatt resists the suggestion that this 'idea of the idea' is merely a discursive device. It is instead an organizing principle, a means of making some sense of situations in which there is great diversity and complexity. The idea of the idea is contingent rather than transcendental, a work in progress rather than a timeless, immutable and finished product. Universities are notoriously diverse and complex, and yet we need to be able to imagine the possibility that different institutions have, as Wittgenstein put it, some 'family resemblance'. For, Rothblatt asks, what use is the alternative? If we cannot imagine the possibility of what it is that marks a university as a university, then perhaps, as we noted earlier with the extreme relativist position, anything goes? In this scenario, any educational institution can be a university if I choose to say it is. Faced with this prospect, even Rothblatt's discontents who are sceptical of essences might want to argue, as he himself does, that the idea of the idea of the university is useful. Without it, he suggests, "a university is utterly shapeless and possesses no means of distinguishing itself from any other kind of educational institution" (Rothblatt, 1997, p.43).

\section{The possibility of the idea of the idea of physical education}

It is in this same sense of an organizing principle, as an as if proposition, that I intend the idea of the idea of physical education to be understood. In using this notion of the $\mathrm{id}^{2}$ of physical education we accept that there is no transcendent, immutable and finished Physical Education; there is no primary Platonic form behind the shadow-world of everyday life. But in order to make sense of a diverse and complex set of practices, we can in applying the $\mathrm{id}^{2}$ of physical education imagine the possibility of some family resemblance among practices that allow us to recognize them as physical education or, conversely, to disallow them this description or, in the basic sense recognized by philosopher John Wilson (2003), at the very least to allow us to have a conversation in which we can sensibly dispute each others' views.

Wilson (2003) has proposed that it is not possible to have a meaningful conversation about the nature of education, for example, without agreeing what the concept of education 
might or might not mean. He insists that there are two ways in which the word concept might be used, and suggests that in analytical philosophy of education both senses were sometimes used though it was rarely explicitly acknowledged which. One is a contextbound sense in which we might speak of, for example, the Victorian concept of laissezfaire in the context of the Industrial Revolution; in this example, use of the word concept is attached to what Wilson calls 'empirical facts'. Another is a more rarefied sense in which we identify the meaning of a concept, which exists for Wilson 'in a purely logical space'. It is this second sense that Wilson claims analytical philosophers sought to conduct their inquiries, though they did not always explicitly say so.

There is also a hierarchical order between these two senses of the word concept, whereby "we can distinguish an enquiry into the nature of things from an enquiry into the meanings of words" (Wilson, 2003, p.102). Wilson assumes then that an inquiry into the meaning of words in a purely logical space must come before an empirical inquiry into the nature of things or otherwise, he asks, how are we to know what we are talking about? From a social epistemological perspective, however, the questions that might be asked of Wilson are 'for whom is a concept meaningful, for what purposes, and in what contexts is the question being asked?'. In other words, a social epistemology would invert the order of Wilson's process by arguing that concepts of education or physical education are only meaningful in relation to the practices that take place in their name. In addition, the purely logical space Wilson envisages needs to be viewed as a context in itself, populated by philosophers like himself. At the same time, the notion of the $i \mathrm{~d}^{2}$ fulfils a similar if not identical function as his sense of concept relating to the meaning of words insofar as it provides an organizing principle, conceptualizing practice. In other words, the $\mathrm{id}^{2}$ is empirically-informed or practice-referenced (in Wilson's context-bound use of the word concept) and to an extent serves the function of the concept concerned with meaning, but always qualified by meaning for whom, for what purposes, in what socio-historical contexts.

The $\mathrm{id}^{2}$ of physical education is not, then, simply a broad definition. It is not a statement of what we wish physical education might be, but of how we make sense of the range of practices that go on in the name of physical education. As I elaborate in the book, the $\mathrm{id}^{2}$ of physical education is an outcome of the embedding of school physical education in physical culture, a process defined technically within Bernstein's (2000) theory of the social construction of pedagogical discourse as the embedding of instructional discourse in regulative discourse. It is well-suited to a social epistemological approach to the curriculum that recognizes subjects are defined by what people do and say rather than only by the 
logical word games played by analytical philosophers or definitions constructed by policymakers and authors of books. At the same time, these word games of philosophers, policy-makers' and authors writing definitions, aims and syllabuses are also empirical activities that go on in the name of physical education and so contribute to our understanding of the diversity and complexity of practice.

I argue in the book that one id ${ }^{2}$ of physical education dominates contemporary physical education practice. This $\mathrm{id}^{2}$ of physical education-as-sport-techniques is the organizing principle of contemporary practice that goes on in the name of physical education. Rather perversely, give the thesis of curriculum history that institutions and school subjects regularly re-invent themselves, I argue that this $\mathrm{id}^{2}$ of physical education has endured for more or less 60 years and has all the appearance of immutability. In the book I explore the evidence to support this claim before going on to recount the historical circumstances that lead to the emergence of this $\mathrm{id}^{2}$, that contributed to its longevity and which may also lead to its demise. Today, to conclude this account of the notion of the $\mathrm{id}^{2}$ of physical education, I want to consider four important relational issues for institutionalized educational practices of all kinds.

\section{Relational issues for the $\mathrm{id}^{2}$ of physical education}

There have been a number of rival ideas of physical education, such as Swedish versus educational gymnastics or a motor-skills approach to games versus Teaching Games for Understanding. Disputes between physical educators, insofar as they exist, are often at this level, contesting one idea of physical education over another. I will argue that much though not all of this argumentation literally misses the 'bigger picture', the broader organizing principle of the dominant form of physical education at any given time or, in other words, the $\mathrm{id}^{2}$. In order to more fully comprehend the nature of the $\mathrm{id}^{2}, \mathrm{I}$ suggest there are four relational issues that physical education along with all other institutionalized forms of educational practice must take into account.

These are, first, the wider field of knowledge which gives the institutional form of knowledge (eg. 'the school subject') its legitimacy and currency, in Bernstein's (2000) terms the regulative discourse produced in the field of the production of pedagogic discourse in which instructional discourse is embedded. Second, all forms of instructional discourse in schools and universities must confront the issue of transfer of learning and the relationship of learning in educational institutions to work, play and life in general beyond the institutions (Lave, 1997). Thirdly, as social practices in the sense intended by MacIntyre (1985), school and university subjects and in particular their value within and 
beyond the academy will be determined by how they define standards of excellence and, therefore, notions of 'ability'. Fourth, all institutionalized educational practices will be shaped by those aspects of the valued culture and heritage of societies they seek to transmit to new generations, and their role in cultural critique and renewal (Chanan and Gilchrist, 1974; Friere, 1973; Giroux, 1981).

In physical education, these issues take on a specific form. For the $\mathrm{id}^{2}$ of physical education, we need to ask questions of the relationship of school physical education to physical culture; transfer of learning beyond the school; how excellence is defined and how it in turn defines 'ability'; and the ways in which physical education is active in cultural transmission, reproduction and renewal. I only have space and time today to introduce each issue briefly in the context of this account of the $\mathrm{id}^{2}$ and leave you to read about them in more detail in chapter six the book.

\section{Physical Culture}

As I will use the notion here, physical culture is a specialized form of corporeal discourse concerned with meaning-making centred on the bodily practices which constitute organized and institutionalized activities such as sport, exercise, active leisure (Kirk, 1999). The purposefully moving body is of particular importance within physical culture. Corporeal discourse in turn is a broader concept referring to all meaning-making activity centred on the body and includes the operation of corporeal power. Corporeal discourse consists of a vast array of what anthropologist Marcel Mauss (1973) called 'techniques of the body' and is produced in what Bernstein (2000) named the field of production of pedagogic discourse. Both corporeal discourse and physical culture are the nonpedagogical raw materials, the regulative discourse, out of which the instructional discourse of school physical education is constructed; the $\mathrm{id}^{2}$ of physical education, physical education's 'pedagogic discourse' in Bernstein's terms, is the conjoining of specific forms of school physical education and selected aspects of physical culture.

As they emerged in government schools for 'the industrial age' (Lawson, 2009) in Australia, Britain, the USA and elsewhere towards the end of the nineteenth century, forms of school physical training were practices that had the explicit though often unstated purpose of regulating and normalizing working-class children's bodies through precise formal exercises carried out in unison within large groups or classes. A primary purpose of corporeal regulation through schooling was the creation of a population of productive but compliant workers and citizens. Elsewhere (Kirk, 1998) I have argued that as the $\mathrm{id}^{2}$ of physical education shifted from gymnastics to sport-techniques so too did the operation of 
corporeal power, moving from what Foucault (1977) more generally referred to as a shift from a 'heavy, ponderous and meticulous' form of corporeal power to a 'looser form of power over the body'.

In order to consider physical education futures, we need to understand how physical culture is changing, its shifting relationship to corporeal practices more broadly, and how new forms of corporeal power emerge. We need to ask what kinds of bodies are constructed by and for physical culture and whether these are forms of embodiment we value and desire (Penney and Chandler, 2000). How might various forms of physical education socially construct bodies in ways that best equip our children for useful, fulfilling and productive lives?

\section{Transfer of Learning}

The school as an institution is not a neutral relay of physical cultural and other knowledge and values. The ways in which schools are structured as institutions and, indeed, have continued to be structured since the late 1800s, around manipulations of time and space through the timetable and classroom, the gym, the laboratory and the assembly hall, set parameters for what might be learned in physical education. We might ask two specific questions here. First, how does the learning that occurs within the school relate to the life beyond the school gates? We need to recognize that it is the same child who plays soccer in physical education class and soccer for the local community club, or who supports a particular professional soccer team. In what sense might school learning and learning in other settings be meaningful to young people, and how does each setting relate to the other? Second, how does school physical education during childhood and adolescence relate to the needs of adulthood? For example, is it merely preparation for an active lifestyle? What, in short, and echoing Chanan's and Gilchrist's (1974) question of the school more broadly, is physical education for? How, specifically, might learning in school physical education transfer beyond the school?

\section{Standards of Excellence and Ability}

Standards of excellence feature prominently in educational institutions because education systems place a high value on testing, assessment and examinations. In this context, physical educators have struggled with the question 'what is ability in physical education?' (Evans, 2004), and their inability to agree an answer to this question may have contributed to their often-cited marginal role in the academy. I suggest in the book that agreement on how to formulate standards of excellence in physical education has been a massive 
challenge for physical education-as-sport-techniques, and represents a significant impediment to its survival in schools.

\section{Cultural Transmission, Reproduction and Renewal}

An increasing volume of research in physical education over the past twenty years has recognized that physical education reproduces valued aspects of the cultural heritage of society such as sports and games (eg. Siedentop, 1994). In so doing, physical education has also reproduced social inequalities concerning gender (Flintoff and Scraton, 2001), ethnicity (Benn, 2005), social class (Evans and Davies, 2008) and disability (Fitzgerald, 2009). As physical education's role in social and cultural reproduction has been increasingly acknowledged, it has also been claimed that physical education could offer opportunities for cultural renewal, for example, for new ways of understanding the social construction of the body (Evans et al., 2004).

The relationship between forms of school physical education and physical culture is the primary matter for consideration here since the nature of this relationship determines the possibility and contents of transfer of learning, the activities that contain standards of excellence, and the specific form of cultural transmission and renewal. Indeed, as I already suggested in this paper, it is this conjoining of forms of school physical education and aspects of physical culture that creates the id ${ }^{2}$ of physical education; in Bernstein's (2000) terms, the instructional discourse of school physical education is embedded in the regulative discourse of physical culture to produce the pedagogic discourse of the $\mathrm{id}^{2}$ of physical education. The id ${ }^{2}$ of physical education-as-sport-techniques is produced by the juxta-positioning of a particular version of physical culture with a particular form of physical education strongly shaped by the school as an institution. While the relationship between forms of school physical education and physical culture is of primary importance, the four relational issues together construct and constitute the notion of the $\mathrm{id}^{2}$ of physical education.

\section{Conclusion}

My purpose in this paper has been to outline how, within a social epistemological approach to defining physical education, the construct of the $\mathrm{id}^{2}$ of physical education might be deployed as an organizing principle and a means of conceptualizing practice. Rather than defining physical education through conceptual analysis in a 'purely logical space', the $\mathrm{id}^{2}$ offers a means of identifying practices as physical education in different places and at different times in history without resort to seeking transcendental features or 
essences. It is, following Rothblatt's lead, an as if principle; this principle considers the possibility of 'the idea of the idea' without making a commitment to seeking the essence of physical education. The $\mathrm{id}^{2}$ of physical education accepts the social constructionist perspective that the school curriculum is the product of a range of social forces, involving the exercise of power and the selection of particular values and beliefs, and that the curriculum changes through struggles between vying groups, without accepting a position of extreme relativism that such a perspective could entail, that is, that anything goes. Instead, the $\mathrm{id}^{2}$ of physical education allows us to identify clusters of common institutionalized practices that taken together amount to a recognizable and particular configuration of knowledge, with a specific relation to physical culture, a view of transfer of learning, a notion of excellence, and a mission for social and cultural transmission and renewal.

In the book, my hope is that for the reader it becomes increasingly obvious why it has been necessary to manufacture this as if principle of the $\mathrm{id}^{2}$. When physical educators in the USA engaged in the so-called 'battle of the systems' in the late 1800s (Ennis, 2006), as did the female gymnasts in Britain in the 1940s (Fletcher, 1984), the disputes were merely between rival ideas of physical education, between versions of the same configuration of knowledge. When the practice of physical education swung away from gymnastics towards sport-techniques sometime between the 1920s and the 1950s, the struggle was indeed at the level of the $\mathrm{id}^{2}$. I suggest in the book that the biggest and single-most significant barrier to renewing physical education has been the failure to understand the $\mathrm{id}^{2}$ of physical education and to mistake it instead as simply one of a number of rival ideas of physical education.

This is not to say that all analysts of physical education, particularly those concerned with change and about the future, have missed this point. The nature of the problem has been plain to a considerable number of researchers. Or, at least, they have recognized the effects of the $\mathrm{id}^{2}$. But rarely have they named the $\mathrm{id}^{2}$ fully, in all its complexity, in any thorough-going contemporary and historical study. There has been no shortage of good ideas for reforming physical education. But they have fallen short because they have mostly failed to confront the $\mathrm{id}^{2}$ squarely, explicitly, and to have insisted on the kind of radical changes to practice that are required to overcome the currently dominant $\mathrm{id}^{2}$ of physical education-as-sport-techniques. 


\section{References}

Becher, T. and Trowler, P. R. (2001) Academic Tribes and Territories, $2^{\text {nd }}$ edn, Buckingham: SRHE and Open University Press.

Benn, T.C. (2005) "'Race” and physical education, sport and dance, in K.M.Green and K. Hardman (eds.) Physical Education: essential issues, London: Sage.

Bernstein, B. (2000) Pedagogy, Symbolic Control and Identity: theory, research, critique, London: Rowman and Littlefield Publishers.

Brownell, C.L. and Hagman, E.P. (1951) Physical Education - foundations and principles, New York: McGraw-Hill.

Chanan, G. and Gilchrist, L. (1974) What School Is For, London: Methuen.

Ennis, C.D. (2006) 'Curriculum: forming and reshaping the vision of physical education in a high need, low demand world of schools', Quest, 58: 41-59.

Evans, J. (ed) (1986) Physical Education, Sport and Schooling, Lewes: Falmer.

Evans, J. (2004) 'Making a difference? education and 'ability' in physical education', European Physical Education Review, 10:95-108.

Evans, J. and Davies, B. (2008) 'The poverty of theory: class configurations in the discourse of Physical Education and Health (PEH)', Physical Education and Sport Pedagogy, 13: 199-214.

Evans, J, Davies, B. and Wright, J. (eds) (2004) Body Knowledge and Control: studies in the sociology of physical education and health, London: Routledge.

Flintoff, A. and Scraton, S. (2001) 'Stepping into active leisure? Young women's perceptions of active lifestyles and their experiences of school physical education', Sport, Education and Society, 6: 5-22.

Fitzgerald, H. (ed) (2009) Disability and Youth Sport London: Routledge.

Fletcher, S. (1984) Women First: the female tradition in English physical education 18801980, London: Althone.

Foucault, M. (1977) Discipline and Punish: the birth of the prison, New York: Allen and Unwin.

Friere, P. (1973) Pedagogy of the Oppressed, New York: Seabury Press.

Giroux, H.A. (1981) Ideology, Culture and the Process of Schooling, Lewes: Falmer.

Goodson, I. F. (1985) 'Towards curriculum history, in I.F. Goodson (ed.) Social Histories of the Secondary Curriculum: subjects for study, Lewes: Falmer.

Goodson, I.F. (1997) The Changing Curriculum: studies in social construction, New York: Peter Lang. 
Hirst, P.H. (1974) Knowledge and the Curriculum, London: Routledge and Kegan Paul.

Kirk, D. (1992) Defining Physical Education: the social construction of a school subject in postwar Britain, London: Falmer.

Kirk, D. (1998) Schooling Bodies: school practice and public discourse 1880-1950, London: Leicester University Press.

Kirk, D. (1999) 'Physical culture, physical education and relational analysis', Sport, Education and Society, 4: 63-73.

Kirk, D. (2009) Physical Education Futures, London: Routledge.

Kleibard, H.M. (1986) The Struggle for the American Curriculum, New York: Routledge.

Laker, A. (2003) 'The future of physical education: is this the "new pedagogy"?', in A. Laker (ed.) The Future of Physical Education: building a new pedagogy, London: Routledge.

Lave, J. (1997) 'The culture of acquisition and the practice of understanding', in D. Kirshner and J.A. Whitson (eds.) Situated Cognition: social, semiotic and psychological perspectives, Mahwah, NJ: Erlbaum.

Lawson, H.A. (2009) 'Paradigms, exemplars and social change', Sport, Education and Society, 14: 77-100.

Lawton, D. (1983) Curriculum Studies and Educational Planning, London: Hodder and Stoughton Educational.

Locke, L.F. (1992) 'Changing secondary school physical education', Quest, 44: 361- 372.

Morgan, R.E. (1973) Concerns and Values in Physical Education, London: Bell.

MacIntyre, A. (1985) After Virtue: a study in moral theory, $2^{\text {nd }}$ edn, London: Duckworth.

Mauss, M. (1973) 'Techniques of the body', Economy and Society, 2: 70-87.

Munrow, A.D. (1963) Pure and Applied Gymnastics, $2^{\text {nd }}$ edn, London: Bell.

National Professional Development Program Health and Physical Education Project (1997) Reviewing the Curriculum in Health and Physical Education Key Learning Area: a model for professional development using the Health and Physical Education Statement and Profile for Australian Schools, Canberra: DEETYA.

Penney, D. and Chandler, T. (2000) 'Physical education: what future(s)?', Sport, Education and Society, 5: 71-87.

Peters, R.S. (1966) Ethics and Education, London: Allen and Unwin.

Randall, Martin (1967) Modern Ideas on Physical Education, $3^{\text {rd }}$ edn, London: Bell.

Rothblatt, S. (1997) The Modern University and Its Discontents: the fate of Newman's legacies in Britain and America, Cambridge University Press. 
Scottish Education Department/ Consultative Committee on the Curriculum (1977) The Structure of the Curriculum in Years 3 and 4 of Scottish Secondary Schools, Edinburgh: HMSO.

Skilbeck, M. (1984) School-Based Curriculum Development, London: Harper and Row.

Siedentop, D. (ed) (1994) Sport Education: quality PE through positive sport experiences, Champaign: Human Kinetics.

White, J. (1973) Towards a Compulsory Curriculum, London: Routledge and Kegan Paul.

Whitty, G. (1985) Sociology and School Knowledge: curriculum theory, research and politics, London: Routledge.

Wilson, J. (2003) 'The concept of education revisited', Journal of Philosophy of Education, 37: 101-108.

Young, M.F.D. (ed) (1971) Knowledge and Control: new directions for the sociology of education, London: Collier-Macmillan. 